\title{
Experiência Subjetiva no Exercício da Monoparentalidade
}

\author{
Sibely Joaquina Pereira Lima* \\ Pontifícia Universidade Católica do Rio de Janeiro - PUC-Rio, Rio de Janeiro, RJ, Brasil \\ ORCID: http://orcid.org/0000-0001-9182-0597 \\ Terezinha Féres-Carneiro** \\ Pontifícia Universidade Católica do Rio de Janeiro - PUC-Rio, Rio de Janeiro, RJ, Brasil \\ ORCID: http://orcid.org/0000-0002-0564-7810
}

\begin{abstract}
RESUMO
Este estudo tem como objetivo investigar a experiência subjetiva no exercício da monoparentalidade. Foram entrevistados cinco mulheres e três homens, entre 35 e 58 anos, das camadas socioeconômicas médias da população urbana do Rio de Janeiro. Trata-se de famílias planejadas: uma com filho biológico, outra com filhos biológicos e adotados, e seis constituídas por adoção. Os resultados foram analisados conforme o método de análise de conteúdo, na sua vertente categorial. Da avaliação do material surgiram duas categorias de análise relacionadas às experiências subjetivas narradas pelos participantes: contexto da escolha e preconceito. Os resultados apontaram que a monoparentalidade foi o meio encontrado para realizar o desejo de ter filho(s) e o contexto dessa escolha é permeado por fatores socioculturais como religião, papéis sociais de gênero e, principalmente, conjugalidade, ressaltando a tendência na família contemporânea de separação entre parentalidade e conjugalidade. $\mathrm{O}$ preconceito atinge mais os homens que as mulheres, envolve questões de gênero relacionadas à afetividade, ao cuidado e à forma de construir família, e aponta para estereótipos atuantes no pensamento social que se presentificam, inclusive, em âmbito institucional.
\end{abstract}

Palavras-chave: família, monoparentalidade, subjetivação, escolha, preconceito.

\section{Subjective Experience in the Exercise of Single Parenting}

\begin{abstract}
This study aims to investigate the subjective experience in the exercise of single parenting. Five women and three men, between 35 and 58 years old, from the middle socioeconomic strata of the urban population of Rio de Janeiro, were interviewed. These are planned families: one with a biological child, another with biological and adopted children, and six constituted by adoption. The results were analyzed according to the content analysis method, in its categorical aspect. From the evaluation of the material, two categories of analysis emerged related to the subjective experiences narrated by the participants: the context of choice and prejudice. The results showed that single parenting was the means found to fulfill the desire to have child(ren) and the context of this choice is permeated by socio-cultural
\end{abstract}

ISSN $1808-4281$ 
factors such as religion, gender social roles and, mainly, conjugality, highlighting the tendency in the contemporary family of separation between parenting and conjugality. Prejudice affects men more than women, involves gender issues related to affectivity, care and the way of building a family, and points to stereotypes that are active in social thinking, which are present even in the institutional context.

Keywords: family, single parenting, subjectivation, choice, prejudice.

\section{Experiencia Subjetiva en el Ejercicio de la Monoparentalidad}

\section{RESUMEN}

Este estudio tiene como objetivo investigar la experiencia subjetiva en el ejercicio de la monoparentalidad. Se entrevistaron a cinco mujeres y tres hombres, entre 35 y 58 años, de estratos socioeconómicos medios de la población urbana de Río de Janeiro. Se trata de familias planificadas: una con hijo biológico, otra con hijos biológicos y adoptados y seis compuestas por adopción. Los resultados se analizaron según el método de análisis de contenido, en su vertiente categorial. De la evaluación del material surgieron dos categorías de análisis relacionadas con las experiencias subjetivas narradas por los participantes: contexto de elección y prejuicio. Los resultados mostraron que la monoparentalidad fue el medio encontrado para cumplir el deseo de tener hijo(s) y el contexto de esta elección está afectado por factores socioculturales como la religión, los roles sociales de género y, principalmente, la conyugalidad, destacando la tendencia en la familia contemporánea a la separación entre paternidad y conyugalidad. El prejuicio afecta más a los hombres que a las mujeres, involucra cuestiones de género relacionadas con la afectividad, el cuidado y la forma de construir una familia, y apunta a estereotipos activos en el pensamiento social, que están presentes incluso en el contexto institucional.

Palabras clave: familia, padres solteros, subjetivación, elección, prejuicio.

As famílias monoparentais fazem parte da diversificação e complexificação das formas de família e de parentalidade na sociedade contemporânea (Solis-Ponton, 2004). Os avanços científico-tecnológicos da medicina e o ingresso das mulheres no mercado de trabalho possibilitaram e afetaram os novos arranjos familiares. Em uma época de aceleradas transformações sociais, Berenstein (2015) salienta a mudança de paradigma após maio de 1968 relacionada à crise da representação, que atingiu várias áreas do conhecimento e também a noção de parentesco em sua conceituação estrutural. No parentesco havia o lugar do pai, da mãe e do filho, lugares que antecediam àqueles que deveriam ocupá-los. Desde então, começou-se a contestar os modelos preconcebidos e a enxergar que, para além da estrutura, 
havia sujeitos em relação e que os lugares do parentesco eram um investimento. Um sujeito era tal e, além disso, investia-se como filho, mãe ou pai.

O conceito de parentalidade é relativamente recente e Magalhães, Féres-Carneiro, Machado e Mello (2015) traçam um breve histórico ressaltando que Freud, ao analisar os estudos sobre as origens psíquicas do parentesco, inaugura um campo de estudos que o diferencia de parentalidade. Essa noção foi desenvolvida por psicanalistas no final dos anos 1950 para designar um processo maturativo, mas, desde os anos 1980, o termo tem sido usado para designar as funções e papéis parentais. Desse modo, a parentalidade passa a ser compreendida como o estudo dos processos psicológicos que se desenvolvem a partir dos vínculos pais/filhos (Solis-Ponton, 2004).

Um dos eixos constitutivos da parentalidade é aquele denominado como experiência da parentalidade, conforme aponta o trabalho de Houzel (2004), oriundo do acompanhamento e análise de famílias cujas problemáticas encontravam-se sob os domínios jurídicos, terapêuticos ou da assistência social. Assim, a experiência do sujeito nesse estudo envolve o aspecto subjetivo, consciente e inconsciente, do fato de vir a ser pai/mãe; de preencher papéis parentais, o que inclui o desejo pelo filho; do desejo de transmitir o que foi recebido, enfim, de todo o processo de transição em direção à parentalidade. Os outros eixos são o exercício, que se refere aos direitos e deveres prescritos pela sociedade e aos interditos próprios de determinada cultura; e a prática que tange os cuidados físicos e psíquicos junto aos filhos. Esses três eixos se articulam sem que haja privilégio de um em detrimento de outro.

Entre as formas de parentalidade, as famílias monoparentais constituem renovado objeto de pesquisa porque crescem em número e sofrem transformações. Dados internacionais apontam um crescimento significativo da monoparentalidade nas últimas décadas, embora seus índices variem conforme as nações. No Reino Unido, segundo o Office for National Statistics (2017), o número das famílias monoparentais cresceu em torno de 15,2\% entre 1996 e 2017. Na França, o crescimento é contínuo e, conforme as análises do Instituto Nacional de Estatística (Insee Analyses, 2019), as famílias monoparentais com filhos com idade inferior a 25 anos representavam mais de 23\% das famílias francesas em 2015.

Esse crescimento se acompanha das mudanças de características nas figuras parentais. Em primeiro lugar, elas se masculinizaram. No continente europeu, segundo dados do Inseé Références (2015), em 2012, 15\% dos representantes de famílias monoparentais eram homens, ou seja, cinco pontos percentuais a mais que em 1996. Em segundo lugar, a participação dos viúvos e viúvas caiu de $15 \%$ em 1996 para 6\% em 2012, ao passo que as 
famílias daqueles que nunca se casaram passaram a representar $36 \%$ do total, 16 pontos a mais que em 1996.

No Brasil, em 1988, o arranjo monoparental foi reconhecido como uma entidade familiar. Dados do IBGE (2016) referentes a arranjos familiares com filhos residentes estimam em $26.8 \%$ o número de lares com responsável feminino, sem cônjuge e com filho(s) e em 3,6\% aqueles com responsável masculino. Entretanto, essa sondagem aborda os núcleos monoparentais indistintamente, quer sejam constituídos por viúvos, divorciados ou solteiros, de modo que os dados nacionais não contemplam as especificidades pertinentes ao contexto da monoparentalidade. Na Europa (Inseé Références, 2015), a monoparentalidade é decomposta em sete grupos de famílias: viúvas e viúvos (6\%); pais não viúvos (11\%), sendo dois terços divorciados; mães com três ou mais filhos (11\%), divorciadas e solteiras; mães que vivem em uma família com três gerações (13\%), mais jovens que a média; mães divorciadas (32\%); mães solteiras com maternidade precoce (10\%) e mães solteiras sem maternidade precoce (16\%). A partir da diversidade de trajetórias percorridas por essas famílias, percebemos que a monoparentalidade constitui-se como uma categoria muito heterogênea, com características variadas, fazendo com que cada situação tenha uma dinâmica muito própria de acordo com a forma de ingresso, a idade dos pais, dos filhos, gênero da figura parental, condições socioeconômicas, a origem da criança e as relações envolvidas no seu nascimento, por exemplo (Bundesministerium für Familien Senioren Frauen und Jugend [BMFSFJ], 2012).

Este mundo heterogêneo, onde pais e mães confrontam-se com diferentes adversidades, promove desafios tanto para as políticas sociais quanto para a pesquisa (Letablier \& Wall, 2018). Assim, o maior desafio no que se refere a pesquisas sobre a monoparentalidade consiste no estudo dessas famílias em suas especificidades. A análise de dinâmicas de famílias originadas do divórcio será bem diferente daquela de uma família na qual o cônjuge é totalmente ausente ou mesmo inexistente.

Ao lado das transformações ocorridas na monoparentalidade, essas famílias têm sido estudadas sob diferentes perspectivas. As primeiras transformações ocorreram com o surgimento da expressão "famílias monoparentais", que se deu em 1975 com a socióloga feminista Andrée Michel, de modo que as até então chamadas "filhas mães" foram qualificadas como mães solteiras (Weissman, 2015). A expressão "famílias monoparentais" contribuiu para o enfraquecimento dos estigmas sociais associados ao divórcio e à maternidade sem casamento (Biasutti, 2016). Dado que, inicialmente, o crescimento de famílias monoparentais foi, predominantemente, constituído por mães solteiras quase todas as 
pesquisas focalizavam este grupo (Goldscheider, Scott, Lilja \& Bronte-Tinkew, 2015) e muitas delas ressaltavam a ideia de déficit em relação às famílias biparentais, consideradas "normais", capazes de oferecer recursos às crianças (Biasutti, 2016). Sobre esse aspecto, Berenstein (2015), ao propor uma concepção vincular para pensar os relacionamentos humanos, faz uma proposição provocadora: se do ponto de vista biológico, fazem falta dois gametas para dar origem ao embrião, a partir da subjetividade talvez não façam falta dois pais. Se o óvulo pode ser fecundado em um tubo de ensaio por um espermatozoide, se o sêmen pode ser congelado e, com a morte do doador, ser usado posteriormente, o parentesco, necessariamente, deveria ser modificado em sua conceituação. Desse modo, o três perde o lugar central - apesar de não deixar de ser importante - mas aparece o dois. O autor propõe desenvolvermos uma nova maneira de pensar as famílias monoparentais.

Nessa linha de pensamento, a constituição das famílias monoparentais não pode mais ser considerada somente quando ocorre a morte do cônjuge ou o abandono. As novas técnicas procriativas e os projetos de vida pessoal, entre outros fatores, contribuem para o crescimento das famílias monoparentais. Conforme ressaltam Leão, Porta, Pauli, Antoniazzi e Siqueira (2017), desde a virada do milênio, cada vez mais mulheres optam por exercer a maternidade sem um companheiro. Aquelas que adquiriram qualificação profissional, independência financeira e que se utilizam das novas técnicas de fertilização por doação de esperma ou da adoção para vivenciar a maternidade, são denominadas como "mães solteiras por escolha", termo usado por Golombok, Zadeh, Imrie e Freeman (2016). Adicionalmente, os homens passaram a desejar vivenciar a parentalidade sem um comprometimento com o cônjuge. Segundo reportagem de 14/08/2016 do jornal $O$ Globo, dados do Cadastro Nacional de Adoção registram pelo menos cinco mil pessoas solteiras na fila de adoção. Desde 2014 o cadastro não especifica o gênero dos pretendentes, mas em 2014, dos 31,6 mil inscritos, 202 eram homens solteiros.

Considerando as aceleradas transformações no mundo em que vivemos, os laços familiares são mais vitais do que nunca tornando-se importante compreender tanto os desafios que as famílias enfrentam quanto os processos familiares que possibilitam que elas prosperem. Uma vez que o tema das famílias monoparentais ganha cada vez mais visibilidade e ainda são poucos os estudos que as considerem em suas peculiaridades (Biasutti, 2016), desenvolvemos esta pesquisa de modo a aprofundarmos e abrangermos algumas das diversas e complexas questões trazidas por elas na atualidade. A partir dessas considerações, tivemos como objetivo investigar a experiência subjetiva no exercício da monoparentalidade. 


\section{Método}

\section{Participantes}

Participaram do estudo oito sujeitos - cinco mulheres e três homens - com idades entre 35 e 58 anos, oriundos das camadas socioeconômicas médias e residentes na região metropolitana do Rio de Janeiro. A idade dos filhos variou entre três anos e seis meses e doze anos. Como critério de participação no estudo, o sujeito deveria ser um adulto, responsável sozinho pela criação de pelo menos uma criança ou adolescente. Para apresentação dos resultados, eles foram nomeados como Mãe 1 a Mãe 5, e Pai 1 a Pai 3. O grupo é caracterizado por famílias que foram planejadas: uma tem filho biológico, outra tem filhos biológicos e adotados, e seis são constituídas por adoção.

(P1), 48 anos, engenheiro, mora com o filho de 17 anos que adotou aos 12 anos. Trabalha como autônomo e desenvolve trabalhos com grupos de adolescentes em uma igreja há muitos anos.

(P2), 58 anos, solteiro, mora com o filho de 10 anos que adotou aos oito anos e sete meses, 15 dias após sua aposentadoria como funcionário de um banco estatal.

(P3), 42 anos, militar, solteiro, realizava trabalhos voluntários em instituições com crianças e adolescentes. Mora com os dois filhos: um com 11 anos, adotado aos oito; outro com 12 anos, adotado aos 10 anos.

(M1), 35 anos, solteira, empresária, buscou um genitor para seu filho que, por sua vez, não conseguiu se inserir como pai desde a gestação. Sempre morou com seu filho biológico de nove anos e, recentemente, mora com seu pai divorciado.

(M2), 50 anos, divorciada, cirurgiã-dentista, mora com a filha de três anos e seis meses que adotou com a idade de dois meses. Moram na casa a mãe de 86 anos, viúva, com a doença de Alzheimer e uma sobrinha do ex-marido que faz faculdade e ajuda na casa.

(M3), 43 anos, divorciada, oficial de justiça, mora com dois filhos biológicos de seu casamento (filha de 23 anos e filho de 22), sem contato com o pai, e com dois filhos adotados, filhos biológicos de sua irmã adotiva: uma menina de seis anos adotada com a idade de dois anos e um menino de quatro anos adotado ao nascer.

(M4), 39 anos, solteira, consultora de beleza, mora com a filha de sete anos, que adotou aos dois anos, através da instituição religiosa à qual pertence.

(M5), 53 anos, solteira, advogada, mora com a filha de 10 anos que adotou com a idade de um ano e sete meses. 


\section{Instrumentos}

Como instrumentos de investigação, foram utilizadas fichas biográficas e entrevistas gravadas em áudio que foram transcritas posteriormente na íntegra. $\mathrm{O}$ roteiro semiestruturado das entrevistas foi formulado a partir da revisão de literatura e teve 10 perguntas como base: Como é para você ser mãe/pai na sua família? Como é a relação entre você e seu filho? Na sua concepção de família, quais os limites e regras que você considera mais importantes? O que seu filho significa para você? O que gera conflitos entre vocês? Vocês têm apoio de outas pessoas que ajudam? Na sua infância, como foi a sua relação com o/a seu/sua pai/mãe? Que expectativas você tem em relação ao seu filho? Quais você considera serem os principais desafios? Há ainda algo que você gostaria de falar sobre esse assunto?

\section{Procedimentos}

Os participantes foram indicados inicialmente pela rede de relacionamento do pesquisador e, a seguir, por indicação dos próprios entrevistados. O contato inicial para a marcação das entrevistas foi feito via WhatsApp. As entrevistas foram realizadas individualmente em local, data e hora determinados pelos participantes e tiveram duração média de uma hora. Durante a entrevista, a ordem de abordagem dos temas foi determinada pela fala do entrevistado. Quando os sujeitos não abordaram espontaneamente alguns temas contemplados no roteiro, coube ao entrevistador formular as perguntas correspondentes.

\section{Cuidados Éticos}

O projeto que deu origem à pesquisa foi aprovado pelo Comitê de Ética da instituição onde foi desenvolvido (processo número 12/2018). Todos os participantes assinaram o Termo de Consentimento Livre e Esclarecido autorizando a utilização dos dados colhidos em ensino, pesquisa e publicação sendo a identidade dos participantes devidamente preservada.

\section{Análise dos Dados}

Os dados coletados foram submetidos ao método de análise de conteúdo, em sua vertente categorial, com a finalidade de investigar, a partir do material discursivo, as significações atribuídas pelos entrevistados aos fenômenos (Bardin, 1977/2016). Por meio da 
técnica categorial, foram destacadas categorias temáticas organizadas a partir da semelhança entre os elementos contidos no material coletado. Para tanto, procedeu-se uma "leitura flutuante" agrupando-se dados significativos, identificando-os e relacionando-os até se destacarem as categorias de análise. A experiência subjetiva no exercício monoparental emergiu das narrativas dos entrevistados na medida em que relatavam como era para eles ser mãe/pai em suas famílias. Logo no início dessas narrativas, os participantes expuseram suas experiências prévias à tomada de decisão de ter um filho independentemente de laços conjugais o que deu origem à categoria temática contexto da escolha. As narrativas que exploraram os desafios, ou conformaram-se após a última pergunta aberta, versaram predominantemente sobre a experiência de preconceito originando assim a categoria de mesmo nome. Tendo em vista que o objetivo deste estudo foi investigar a experiência subjetiva no exercício da monoparentalidade, serão apresentadas e discutidas as categorias: contexto da escolha e preconceito.

\section{Resultados e Discussão}

\section{Contexto da Escolha}

No grupo pesquisado, a parentalidade não surgiu por acaso, mas foi planejada de modo que emergem da fala dos entrevistados as circunstâncias que os conduziram a essa tomada de decisão: as motivações e os impasses entre o desejo de vivenciar a parentalidade e os relacionamentos conjugais prévios. Como apontado por Machado, Féres-Carneiro e Magalhães (2015), a literatura ressalta a importância de identificar as motivações para a compreensão do desenvolvimento dos vínculos. A totalidade dos entrevistados apresentou como razão manifesta para a escolha da monoparentalidade o desejo de ter filho. Entretanto, esse desejo é associado a variadas experiências subjetivas.

A narrativa de P1 é paradoxal. Por um lado, estabelece uma relação lógica entre sua experiência prévia com adolescentes e seu desejo de paternidade, por outro, atribui a Deus e a coincidências significativas a realização do seu desejo.

Desde pequeno, nos meus quinze, eu sempre falava, um dia eu vou ter um filho (. . .) Eu sempre trabalhei muito pelo social (. . .) com adolescente (. . .) eu sempre brinco assim, que há 5 anos atrás eu oficializei um filho, porque até então eu sempre tive filhos postiços por aí, que eu (. . .) sempre cuidava, eu sempre orientava, mas não era 
meu filho(. ....)Eu não sabia que eu podia adotar (. . .) e aí, eu também sou muito católico, tudo, sou devoto de São Francisco de Assis (. . .) e eu fui à Itália, viajei, e lá, eu tava rezando e tal, e eu falei, se tiver que ser agora, que eu tenha meu filho agora( ...) passou umas duas semanas, um amigo meu (. . .) conversando com ele sobre isso, “Você quer adotar? (. . .) a minha esposa é advogada de adoção” (. . .) Aí eu falei, é muita coincidência! (. . .) Então eu te falo, não foi uma escolha, foi uma coincidência entre aspas, de um acordo de Deus, que a gente chegou. (Pai 1, 48 anos)

A narrativa de M1 relaciona o seu desejo pela criança a uma instância religiosa, sugerindo um sentimento de predestinação.

Eu queria o N., eu queria essa criança (. . .) porque a minha religião (. . .) eu sou de uma linha espírita, e então eu tenho informações com relação a isso, que são importantes pra mim. Ele veio de umas características e com uma carga espiritual que nós trocamos, de forma que ele é muito amoroso e nós somos, de fato, amigos. (M 1,38 anos)

As duas narrativas atribuem a uma instância sobrenatural a motivação e a tomada de decisão de ter um filho. Ao analisar os desejos envolvidos na parentalidade solitária consideramos que, nos desejos implícitos nessa escolha, pode-se incluir uma amplitude de questões inconscientes que estão envolvidas na vontade de ter filhos, de ser pai/mãe, e na atitude empregada. Conforme Machado et al. (2015), no que concerne às profundezas do inconsciente que baseiam a demanda por um filho, não existe certeza e para cada sujeito isso se configura de modo bem singular. As autoras ressaltam que a história mítica dá um sentido consciente ao desejo da parentalidade, sendo uma forma de expressar questões inconscientes envolvidas nessa escolha. Ratificando essa ideia, destacamos as reflexões de Levy (2005), segundo as quais, as origens inconscientes do desejo costumam ser marcadas por idealizações ou apresentar algo de ficcional.

Em P3, como visto também em P1, a experiência prévia com cuidados de crianças ou adolescentes guarda relação com o desejo de tornar-se pai:

Eu já fazia trabalhos voluntários, então eu tinha contato com essas instituições (. . .) Num desses abrigos, eu descobri um projeto que se chamava de apadrinhamento 
afetivo (. . .) e enfim, eu fui tendo um contato mais a fundo com essa realidade. Ao mesmo tempo, né, não sei, foi crescendo em mim o desejo de ser pai. (P3, 42 anos)

A associação entre a experiência com cuidados e o desejo de ter filho é tradicionalmente pensada em relação às mulheres. Levy e Féres-Carneiro (2002), ao pesquisarem as motivações de mulheres que adotam, estabeleceram uma possível relação entre o trabalho voluntário e o desejo de cuidar, de modo que o contato com uma criança específica pode motivar o desejo de adotar. Entretanto, no caso dos homens, não encontramos na literatura a relação entre a experiência com cuidados de crianças ou adolescentes e o desejo de ter um filho. Acreditamos que a escassez de exemplos como esses esteja relacionada à predominância do modelo de masculinidade hegemônica, conceito introduzido por Connel em 1996, citado por Abade e Romanelli (2018), que estabelece atributos, valores e condutas específicas para os homens segundo os quais estes devem ser fortes, ativos, competitivos e provedores financeiros da família.

No Brasil, a construção da masculinidade predominante não estimula os homens para o cuidado de si ou do outro (Braide et al., 2018). Da mesma forma, se a masculinidade vem sendo alvo de debates nas últimas décadas, a paternidade também é uma construção influenciada pelas mudanças sócio-históricas dos papéis de gênero e por novos arranjos familiares. Assim, o modelo de paternidade, pelo qual cabia ao homem o papel exclusivo de provedor de seu lar, vem sendo reformulado condizendo com as demandas oriundas do movimento feminista e dos novos papéis familiares para os quais o homem tem sido requisitado. Com o aumento do número de separações conjugais e o ingresso das mulheres no mercado de trabalho, hoje, tanto homens como mulheres podem ser provedores de seus lares e precisam conciliar os cuidados com os filhos, o que conduz à reformulação de suas funções. Isto repercute na redefinição dos papéis participativos do pai no cuidado dos filhos e numa nova concepção de paternidade, observando-se que os homens têm buscado transformar os estereótipos do pai tradicional, o que torna possível o exercício de relações mais amorosas com seus filhos (Abade \& Romanelli, 2018).

Para M4, a opção pela monoparentalidade sofre a influência do discurso social, historicamente enraizado, no qual a identidade feminina se constitui no papel de esposa e de mãe.

Eu comecei a entrar em um processo meio que de depressão, né, porque eu tava vendo nada dando certo, né, dos grandes sonhos que eu queria, e um dia minha mãe 
me perguntou (...) porque que eu achava que minha vida tava frustrada, se era porque eu não tinha casado, ou se porque eu não era mãe. Então foi assim, por não ser mãe (. . .) eu jamais faria, por ser evangélica, uma produção independente, mas a adoção não tem o mínimo problema. (M 4, 39 anos)

A pergunta colocada pela mãe de M4, na qual ela relaciona a frustração da filha ao fato de não ser esposa nem mãe, evidencia o determinismo social da maternidade imposto na atualidade para a mulher. Persiste ainda hoje em alguns grupos sociais e no imaginário de muitas mulheres a ideia de que ser mulher é o mesmo que ser mãe (Levy \& Féres-Carneiro, 2002). Apesar dos dados históricos sobre o processo de emancipação e independência feminina, ainda é difícil para a mulher, na atualidade, optar por outros papéis e abrir mão da maternidade uma vez que ser mãe é um papel que lhe foi imposto por muito tempo na história e por meio do qual era possível obter satisfação e reconhecimento (Leão et al., 2017).

Ao lado do desejo de ter um filho, no que se refere ao que conduziu ao planejamento da monoparentalidade, emergiu das narrativas um aspecto articulado ao desejo de parentalidade e conjugalidade. Para ilustrar, seguem duas das falas:

Eu já tinha tido um relacionamento anterior por muito tempo, e eu era muito nova, e eu não queria ter filho naquele momento. Quando eu tive esse meu segundo relacionamento mais sério, eu falei pra ele, "Olha, eu quero ter filho", "Não tem problema”. Ele já tinha filhos adultos (. . .) Nessa virada pros quarenta, ele veio com essa novidade "Eu não quero mais casar" e eu fui ao fundo do poço, pronto, acabou a minha chance de ser mãe (. . .) Até eu me recuperar desse luto (. . .) eu não tinha nem condição de pensar em filho (. . .) Uma colega me convidou para ir na Romão Duarte, no dia das crianças (. . .) ali foi uma pré-semente (. . .) da minha ideia (. . .) Queria ter um companheiro, queria ter um marido? Queria! (. . .) pra ter tido até esse filho com ele, né? Agora, isso não me impediu de querer o que eu sempre quis ser mãe. (M 2, 50 anos)

Quando do primeiro relacionamento que eu tive, eu era recém-formado, ela tava estudando ainda, não era o momento de ter filho. $O$ segundo relacionamento maior que eu tive (. . .) ela já tinha filhos, aí não queria mais ter filhos (. . .) O terceiro chegou, já estava numa idade que não dava mais pra ter filhos, ela (. . .) pelos riscos, 
aí pela idade (. ..) Até que chegou o momento que eu me vi sozinho, e sem realizar aquele meu desejo de ser pai. Entendeu? (P 2, 58 anos)

As narrativas falam sobre os impasses entre a conjugalidade e o desejo de parentalidade. Nos casos de M2, M5 e P2, o(a) parceiro(a) não pôde dividir com a(o) companheira(o) a realização do desejo de ter filhos pelo fato dele(a) já ter os seus. As relações conjugais prévias de M2 e M5, que se sustentavam enquanto tal, dissolveram-se frente ao desejo de parentalidade da parceira. No caso de P2, apesar de suas tentativas, não conseguiu conciliar a realização de seu desejo de parentalidade com a situação conjugal que vivenciava em dois de seus relacionamentos. Conforme a narrativa da maioria dos entrevistados, a instabilidade conjugal revela-se como um dos fatores que predispõe a monoparentalidade (Goldscheider et al., 2015). A partir dessa perspectiva, problematizamos para o grupo estudado, o termo monoparentalidade por escolha ou opção. Se por um lado esses termos acompanharam as transformações ocorridas na história desta estrutura familiar, que se constituía, inicialmente, de mães solteiras cuja monoparentalidade surgia por acaso, por outro, hoje encobre diferentes motivações e modos de realizar e vivenciar a parentalidade. De acordo com a literatura, diferentes aspectos têm sido relacionados à tomada de decisão pela parentalidade solitária. Entre os anos 1960/1970, discutiu-se a questão do livre arbítrio relativo à maternidade solteira, a então chamada produção independente, vista como uma adesão a um projeto individualista que marcava esse período (Levy \& Féres-Carneiro, 2002) e que implicava o desejo da exclusão de um terceiro na formação familiar. Em outro exemplo, Layne, citado por Leão et al. (2017), aponta que o desejo de evitar conflitos e riscos que um casamento ou união estável e um divórcio possam causar constitui motivos para formar família sem um companheiro.

Nos resultados da nossa pesquisa não foi verificada a opção pela configuração monoparental ou a intenção de vivenciar a parentalidade solitária, mas a monoparentalidade aparece como o meio encontrado para realizar o desejo de ter filho. $\mathrm{O}$ que predomina nessa escolha é a força do desejo de vivenciar a relação parento-filial. Borges, Magalhães e FéresCarneiro (2014) ressaltam que o casamento vem deixando de ser o foco principal nos planos de constituir família e os filhos passam a ocupar um lugar mais central. Se outrora esperava-se que o casal conjugal se tornasse o casal parental, atualmente, enquanto os casais jovens postergam cada vez mais o desejo de ter filhos (Bernardi, 2017) em prol da relação conjugal e do desenvolvimento profissional, constatamos que outros indivíduos não encontram com quem compartilhar o desejo de ser mãe/pai. Assim, a monoparentalidade, como aqui 
caracterizada, constitui um dos indicadores da tendência à separação entre conjugalidade e parentalidade na sociedade atual especialmente no caso dos sujeitos que não abrem mão de vivenciar a parentalidade. Esses resultados ratificam as recentes contribuições da psicanálise que demonstram que as relações de consanguinidade e de aliança passam a ser insuficientes para o exercício da parentalidade e tornar-se pai ou mãe passa a depender mais da história individual de cada um e de uma lógica do desejo que da reprodução de um modelo de família nuclear, como no passado (Zornig, 2012).

\section{Preconceito}

Algumas pesquisas (Santos, Fonsêca, Fonsêca \& Dias, 2011; Leão et al., 2017) falam sobre o preconceito experienciado pela parentalidade solteira encontrado na situação de adoção monoparental e tardia e referem-se à ausência de pessoas significativas para ajudar no cuidado da criança devido à não aceitação inicial por parte da família extensa do adotante. As situações de preconceito entre os homens não são explicitadas havendo apenas o depoimento de um participante sobre a necessidade de a sociedade estar mais preparada para as várias possibilidades de se construir uma família (Santos et al., 2011). Nesse trabalho, não houve uma identificação da natureza do preconceito ou uma descrição da experiência que lhe corresponde.

No presente estudo, as narrativas revelam que o preconceito atinge mais os homens que as mulheres. Sobre esse ponto, salientamos que embora o movimento feminista tenha promovido debates sobre questões de gênero e que as transformações sociais e econômicas tenham resultado em maior independência e autonomia da mulher, alterando sua posição na família e na condição materna, o grande número de estudos sobre a condição de gênero feminino não foi acompanhado pela mesma quantidade de pesquisas sobre a posição social do homem na família especialmente quanto à paternagem (Abade \& Romanelli, 2018). Essa noção não se limita aos aspectos biológicos e legais, mas também envolve a afetividade e o cuidado.

Nesta pesquisa, as falas de dois entrevistados revelam o peso da experiência do preconceito em relação aos homens solteiros que adotam - apenas o terceiro deles não falou que foi descrito em três diferentes situações:

Na própria igreja católica, onde eu faço reuniões de liturgia, surge o assunto, às vezes. De novo, família, papapá, tem preconceito, porque é família de homem sem tá 
casado, família de homem solteiro, né? Tem aqueles olhares, "Ah, só pode ser pedófilo pra adotar um adolescente”. Eu tive agora um problema sério na Igreja lá, por uma louca (. . .) que começou a trabalhar comigo na catequese de crisma, e eu senti que ela começou a me olhar assim meio de rabo de olho, porque ( . . .) eu tenho uma turma com 15 adolescentes (. . .) e todos eles são assim comigo, eles chegam, me abraçam, me beijam, a gente chega e conversa, a gente tem muita ligação com todos eles. E aí ela começou a falar por trás de mim na Igreja, chamou o padre pra falar com o padre. A sorte é que o padre é meu amigo. (P 1, 48 anos)

Eu acho que ainda existe muito preconceito em relação ao fato de ser uma família monoparental (. . .). Uma vez, que o M. acabou brigando com um coleguinha aqui no condomínio, a mãe, quando interfonou aqui pra casa, eu que atendi o telefone. Ela falou assim "Eu quero falar com a mãe dele”. Ela já fez todo um cenário, né, ela (. . .) imaginou que ele tinha uma mãe, e que talvez por ela ser mulher, talvez a mãe fosse a melhor pessoa. Ela não perguntou quem é o responsável por ele, né? Da minha parte, eu não sou obrigado a falar (. . .) pra ela, né, que ele não tem mãe. Então eu oriento eles, e eu procuro fazer a mesma coisa, em falar o seguinte "Olha, eles não moram com a mãe deles”. Porque, ao fazer isso (. . .) você não precisa dar detalhe! Sua mãe pode ser divorciada do seu pai! Isso é mais socialmente aceito. (P 3, 42 anos)

Eu fui tirar o CPF do D. (. . .) a menina que tava me atendendo, ela falou que tinha que ter o nome da mãe dele! Eu falei "Não, eu sou o responsável” e ela insistindo. Os sistemas, isso vale pro Detran, pros Correios, pra Receita Federal, eles estão acostumados a colocar o nome da mãe como um campo obrigatório! Como é que você faz com essas famílias que não têm o nome da mãe? (. . .) Um caso dum amigo meu, que também adotou né, enfim, que o filho dele foi tirar a carteira de habilitação de motorista, ele foi sozinho (. . .) ele não conseguiu! Ele sofreu constrangimento, porque a mulher queria que tivesse o nome da mãe! E pra ele explicar que ele não tinha mãe? (. . .) No meu caso, como eu fui lá junto com meu filho, eu tive condições de argumentar com ela. Mas a sociedade não está, de fato, preparada. Eu não cobro isso da sociedade, ao mesmo tempo, tenho obrigação de proteger a minha família. (P 3, 42 anos) 
As narrativas remetem às representações de gênero atuantes no pensamento social que diferenciam valorativamente os modelos de pessoa feminina e masculina e que geram discriminações que afetam especialmente os homens, como no preconceito de que cada homem seria um pedófilo em potencial, por exemplo. Segundo a Agência Francesa de Adoção (AFA, 2008), os homens solteiros carregam o peso das fantasias coletivas ligadas à pedofilia e isso torna a adoção para eles ainda mais difícil do que para elas. Esse preconceito de gênero é o mesmo que atinge os professores do ensino fundamental. Rabelo (2013) aponta que as preocupações e suspeitas de que homens que cuidam de crianças possam ser pedófilos contêm implicitamente o temor da sexualidade masculina e, ao mesmo tempo, corroboram com a ideia de que a mulher não possui impulsos sexuais causadores de perversão.

O relato da experiência relacionada a dificuldades de comunicação no convívio social, por ser de difícil apreensão para outras famílias a existência de um filho sem mãe, leva-nos a considerar que, apesar dos avanços das análises sobre paternidade, essa noção ainda é refém de estereótipos e é comumente associada à provisão material da família. Enquanto a atuação do pai no imaginário social tende a ficar limitada à sua condição de provedor, outras facetas de sua conduta nas relações domésticas, incluindo a dimensão da expressão dos afetos e sua capacidade de cuidar, são colocadas em segundo plano, como se não existissem (Abade \& Romanelli, 2018). A narrativa traz também a percepção de que famílias monoparentais oriundas do divórcio costumam ser mais bem aceitas que aquelas que se constituem desde o início como tal. Dados como esses colocam em evidência a necessidade de que a sociedade esteja mais preparada para lidar com as diversas possibilidades de se constituir família (Santos et al., 2011). Acrescentamos que, apesar do crescimento da monoparentalidade masculina, o grupo de pais sozinhos continua sendo o menos compreendido. Além disso, a pesquisa nesses casos é focada predominantemente nos pais divorciados ou nos separados que obtiveram a guarda dos filhos (Goldscheider et al., 2015).

É importante problematizar o preconceito de gênero em âmbito institucional que gerou constrangimentos e impedimentos na experiência dessas famílias, uma vez que para órgãos governamentais o nome materno constitui um campo obrigatório. Podemos supor que o fato de o nome paterno ser prescindível para as autoridades governamentais esteja ligado a um legado social e cultural, uma vez que, durante muito tempo, o reconhecimento legal dos filhos esteve condicionado ao casamento havendo milhares de crianças em cujas certidões havia a ausência da filiação paterna (Abade e Romanelli, 2018). É relativamente comum no Brasil que muitos filhos de famílias pobres não tenham o nome do pai na certidão de nascimento. Entretanto, com as diferentes trajetórias percorridas pelas famílias contemporâneas e o 
reconhecimento pela Constituição Federal das famílias monoparentais, desde 1988, é surpreendente que não haja uma atualização por parte das instituições públicas em resposta às novas exigências geradas por essas famílias.

Apesar de não encontrarmos na literatura relatos em pesquisas sobre as experiências de preconceito semelhantes às aqui apresentadas, vemos de modo geral alguns pontos em comum com os resultados encontrados por Abade e Romanelli (2018) ao destacarem que, apesar das avaliações negativas sobre a dimensão afetiva e cuidadora do pai na sociedade, existe um interesse crescente dos homens na criação e socialização dos filhos indicando a construção de uma nova forma de vivenciar a paternidade. Acrescentamos que isto se reflete na busca da realização do desejo de ser pai, mesmo na impossibilidade de conciliar esse desejo com a conjugalidade.

Em apenas uma narrativa feminina surgiu a vivência do preconceito:

Eu acho que, ser mãe sozinha, independente da forma como veio, é um desafio muito grande, né, as pessoas julgam independente se foi da barriga ou não, né, tipo assim, acham que você não tem direito a reclamar, porque você que escolheu ser mãe sozinha, então (gargalhada) você não pode reclamar que tá cansada! (M 4, 39 anos)

A fala da entrevistada denuncia o preconceito que culpabiliza a mulher pelo seu sofrimento frente à sobrecarga de atribuições, como na expressão "Foi você que escolheu!". Santos et al. (2011) relacionam o peso do preconceito a uma ausência de criação de estratégias para lidar com as experiências de sofrimento trazidas pela adotante monoparental.

\section{Considerações Finais}

A análise dos dados coletados referentes à experiência dos sujeitos que exercem a parentalidade solitária conduziu-nos a resultados que englobam o percurso que envolve a decisão de ser pai/mãe sozinho(a) e também os desafios enfrentados ao viver em uma sociedade na qual prevalecem representações estereotipadas de gênero e de família.

Em primeiro lugar, destacam-se nas experiências subjetivas dos participantes as motivações que se apresentam de diversas formas. Para a maioria deles aparece como razão manifesta para a monoparentalidade o desejo de ter filho. Em duas falas o desejo é expresso por meio de representações de natureza religiosa, como uma ilustração de sentimentos de predestinação ou para exprimir a inacessibilidade das raízes mais profundas do desejo. Entre 
os homens, para dois deles, a experiência prévia com cuidados de crianças e/ou adolescentes em instituições pôde motivar a demanda por adoção contrariando a representação de gênero de que o homem não teria o dom de cuidar por ser este um atributo feminino. Em uma narrativa feminina, constatou-se a influência do determinismo social da maternidade na motivação para ser mãe, apontando que ainda persiste na atualidade, em alguns grupos sociais e no imaginário de algumas mulheres, a associação entendida como necessária entre identidade feminina e maternidade.

Em segundo lugar, faz parte da trajetória de tornar-se pai/mãe sozinho(a) as dificuldades em conciliar a conjugalidade com a parentalidade. $\mathrm{O}$ desejo de vivenciar a parentalidade associado à instabilidade conjugal característica da sociedade contemporânea ou à ausência de relações amorosas apresenta-se como um fator que predispõe à parentalidade solitária. Dessa forma, a monoparentalidade aparece aqui não como um fim, mas como o meio encontrado para realizar o desejo de ter filho constituindo assim um dos indicadores da tendência à separação entre conjugalidade e parentalidade na sociedade contemporânea.

Outro tipo de experiência subjetiva na trajetória de se tornar pai/mãe sozinho(a) e de exercer papéis e funções parentais refere-se ao preconceito. No grupo pesquisado, pudemos observar que o preconceito atinge mais homens que mulheres devido a representações estereotipadas de gênero. Primeiro, constatou-se o preconceito em relação a homens solteiros que adotam, uma vez que eles carregam o peso das fantasias coletivas ligadas à pedofilia, baseadas no temor da sexualidade masculina, por ser esta considerada ativa em contraposição à natureza presumidamente inofensiva da sexualidade feminina.

Em segundo lugar, estereótipos de gênero são enfrentados no convívio social por ser de difícil apreensão para outras famílias a existência de um filho sem mãe. No pensamento social, a atuação do pai tende a ficar limitada à sua condição de provedor enquanto outras facetas de sua conduta nas relações domésticas, incluindo a dimensão da expressão dos afetos e sua capacidade de cuidar, são colocadas em plano secundário como se não existissem (Abade \& Romanelli, 2018). Representações preconceituosas de gênero estão presentes também nas instituições governamentais e constituem obstáculos na confecção e retirada de documentos perante órgãos públicos, uma vez que para estes, o nome da mãe é considerado campo obrigatório. Pontuamos que, apesar do crescimento da monoparentalidade masculina, o grupo de pais sozinhos continua sendo o menos compreendido. Além disso, a pesquisa, nesses casos, é focada predominantemente nos pais divorciados ou separados que obtiveram a guarda dos filhos o que aponta para a necessidade de maior exploração da monoparentalidade masculina por adoção em futuras pesquisas. Uma das participantes falou de preconceito 
associado à culpabilização pela escolha que fez quando se diz cansada, o que revela que os problemas relativos à ausência de criação de estratégias para lidar com as experiências de sofrimento trazidas por essas mulheres ainda persistem.

Compreendemos como limitações deste estudo o fato de o grupo pesquisado não englobar as dinâmicas referentes às famílias monoparentais que constiuem-se como resultado de morte, separação ou abandono. Além disso, esse grupo não foi formado por famílias das camadas mais pobres da sociedade, que constituem a maior parte das famílias monoparentais do nosso país, nas quais a monoparentalidade está associada, em grande parte, a problemas sociais, de precariedade de recursos materiais, educacionais e emocionais. Igualmente, a pesquisa não abordou as questões específicas relacionadas às famílias monoparentais constituídas por meio de reprodução assistida, cujo número é cada vez mais crescente na sociedade contemporânea.

Entretanto, o grupo estudado revelou que a monoparentalidade foi o meio encontrado para realizar o desejo de ter filho(s), o que nos remete ao pensamento de Berenstein (2015) que compreende o vínculo parento-filial como uma forma de subjetivação, não apenas porque os lugares do parentesco exigem que os sujeitos se tornem diferentes do que eram antes, mas porque o sujeito escolhe estar no lugar parental e o faz de forma ativa, consciente e participativa. Contudo, cabe ainda à rede social desenvolver estratégias para lidar com as novas situações trazidas por essas famílias, o que constitui um tema a ser abordado mais profundamente em outros trabalhos e em novas pesquisas.

\section{Referências}

Abade, F., \& Romanelli, G. (2018). Paternidade e paternagem em famílias patrifocais. Revista Estudos Feministas, 26(2). doi: 10.1590/1806-9584-2018v26n250106

Agence Française de l'Adoption [AFA]. (2008). Cahier Psy 7: L'enfant adopté par un(e) célibataire. Paris: AFA. Retirado de http://www.agence-adoption.fr/lafa-vousinforme/cahiers-psy/7/

Bardin, L. (2016). Análise de Conteúdo. São Paulo: Edições 70 LDA, Almedina Brasil. (Obra original publicada em 1977)

Berenstein, I. (2015). Prólogo. In L. Weisman, Familias Monoparentais (2a, pp. 19-26). São Paulo: Casa do Psicólogo. (Obra original publicada em 2009)

Bernardi, D. (2017). O projeto de ter filhos: Desafios contemporâneos sob a ótica de homens e mulheres (Dissertação de mestrado). Pontifícia Universidade Católica do Rio de 
Janeiro, Rio de Janeiro, RJ, Brasil. Recuperado de https://www.maxwell.vrac.pucrio.br/33425/33425.PDF

Biasutti, C. M. (2016). Parentalidade em casos de adoção monoparental (Dissertação de mestrado). Universidade Federal do Espírito Santo, Vitória, ES, Brasil. Recuperado de http://repositorio.ufes.br/handle/10/9047

Braide, A. S. G., Brilhante A. V., Arruda, C. N., Mendonça, F. A. C., Caldas, J. M. P., . . . Nations M. K. (2018). Sou homem e pai sim! (Re)construindo a identidade masculina a partir da participação no parto. Revista Panamericana de Salud Pública, 42(7), 1-7. doi: 10.26633/RPSP.2018.190

Borges, C., Magalhães, A., \& Féres-Carneiro, T. (2014). Liberdade e desejo de constituir família: Percepções de jovens adultos. Arquivos Brasileiros de Psicologia, 66(3), 89103. Recuperado de http://pepsic.bvsalud.org/pdf/arbp/v66n3/08.pdf

Bundesministerium für Familien Senioren Frauen und Jugend [BMFSFJ]. (2012). Alleinerziehende in Deutschland: Lebenssituationen und Lebenwirklichkeiten von Müttern und Kindern. Monitor Familienforschung, (28), 1-34. Recuperado de https://www.bmfsfj.de/bmfsfj/service/publikationen/alleinerziehende-in-deutschlandlebenssituationen-und-lebenswirklichkeiten-von-muettern-und-kindern-73564

Goldscheider, F., Scott, M. E., Lilja, \& Bronte-Tinkew, J. (2015). Becoming a Single Parent: The Role of Father and Mother Characteristics. Journal of Family Issues, 36(12) 16241650. doi: $10.1177 / 0192513 X 13508405$

Golombok, S., Zadeh, S., Imrie, S., Smith, V., \& Freeman, T. (2016). Single mothers by choice: Mother-child relationships and children's psychological adjustment. Journal of Family Psychology, 30(4), 409-418. doi: 10.1037/fam0000188

Houzel, D. (2004). As implicações da parentalidade. In L. Solis-Ponton (Org.), Ser pai, ser mãe: Parentalidade, um desafio para o próximo milênio (pp. 47-51). São Paulo: Casa do Psicólogo.

Insee Analyses. (2019). Figure 1 (Insee Recensement de la population 2015). Retirado de https://www.insee.fr/fr/statistiques/3714737

Insee Références. (2015). Dossier: Les familles monoparentales en Europe. Paris: Insee. Retirado de https://www.insee.fr/fr/statistiques/2017504?sommaire=2017528

Instituto Brasileiro de Geografia e Estatística. (2016). Síntese de indicadores 2016: Pesquisa nacional por amostra de domicílios 2015. Rio de Janeiro: IBGE. Retirado de https://ww2.ibge.gov.br/home/estatistica/populacao/condicaodevida/indicadoresminim os/sinteseindicsociais2016/default_tab_xls.shtm 
Leão, F., Porta, D., Pauli, C., Antoniazzi, M., \& Siqueira, A. (2017). Reflexões teóricas sobre maternidade e adoção no contexto da monoparentalidade feminina. Pensando Famílias, 21(2), 45-59. Recuperado de http://pepsic.bvsalud.org/scielo.php?script=sci_arttext\&pid=S1679494X2017000200005

Letablier, M.-T., \& Wall, K. (2018). Changing Lone Parenthood Patterns: New Challenges for Policy and Research. In L. Bernardi \& D. Mortelmans (Eds.), Lone Parenthood in the Life Course (pp. 29-53). Cham, Switzerland: Springer International Publishing. doi: 10.1007/978-3-319-63295-7

Levy, L. (2005). Famílias monoparentais adotivas: A importância de uma rede de apoio. In T. Féres-Carneiro (Org.), Família e Casal: Efeitos da contemporaneidade (pp. 50-57). Rio de Janeiro: Puc-Rio.

Levy, L, \& Féres-Carneiro, T. (2002). Famílias monoparentais femininas: Um estudo sobre a motivação de mulheres que adotam. Interação Em Psicologia, 6(2), 243-250. Retirado de https://revistas.ufpr.br/psicologia/article/view/3312

Machado, R., Féres-Carneiro, T., \& Magalhães, A. (2015). Parentalidade adotiva: Contextualizando a escolha. Psico, 46(4), 442-451. doi: 10.15448/19808623.2015.4.19862

Magalhães, A., Fères-Carneiro, T., Machado, R., \& Mello, R. (2015). Autoridade parental e violência familiar: O pai em questão. In T. Fères-Carneiro (Org.), Família e casal: Parentalidade e filiação em diferentes contextos (pp. 25-38). Rio de Janeiro: PUCRio, Propesctiva.

Office for National Statistics. (2017). Families and households 2017. Londres: Autor. Recuperado de https://www.ons.gov.uk/peoplepopulationandcommunity/birthsdeathsandmarriages/fa milies/bulletins/familiesandhouseholds/2017

Rabelo, A. O. (2013). Professores discriminados: Um estudo sobre os docentes do sexo masculino nas séries do ensino fundamental. Educação e Pesquisa, 39(4), 907-925. doi: 10.1590/S1517-97022013005000004

Santos, C. P., Fonsêca, M., Fonsêca, C., \& Dias, C. (2011). Adoção por pais solteiros. Psicologia: Teoria e Prática, 13(2), 89-102. Retirado de http://pepsic.bvsalud.org/pdf/ptp/v13n2/v13n2a07.pdf 
Solis-Ponton, L. (2004). A construção da parentalidade. In L. Solis-Ponton (Org.), Ser pai, ser mãe: Parentalidade, um desafio para o próximo milênio (pp. 29-40). São Paulo: Casa do Psicólogo.

Weissmann, L. (2015). Famílias Monoparentais: Um olhar da teoria das configurações vinculares ( $2^{\mathrm{a}}$ ed.). São Paulo: Casa do Psicólogo.

Zornig, S. A. -J. (2012). Construção da parentalidade: Da infância dos pais ao nascimento dos filhos. In C. A. Piccinini, \& P. Alvarenga (Org.), Maternidade e paternidade: A parentalidade em diferentes contextos (pp. 17-34). Rio de Janeiro: Casa do Psicólogo.

\section{Endereço para correspondência}

Sibely Joaquina Pereira Lima

Rua Prof. Hermes Lima, 120/202, Recreio, Rio de Janeiro - RJ, Brasil. CEP 22795-065

Endereço eletrônico: sibely_lima@yahoo.com.br

\section{Terezinha Féres-Carneiro}

Rua General Góes Monteiro, 08, bloco D/2002, Botafogo, Rio de Janeiro - RJ, Brasil. CEP 22290-905

Endereço eletrônico: teferca@puc-rio.br

Recebido em: 19/09/2019

Reformulado em: 07/09/2020

Aceito em: 09/09/2020

\section{Notas}

* Psicóloga (IBMR, 2015), Especialista em Psicologia Analítica (IBMR, 2000), Mestre (2018, PUC-Rio) e Doutoranda em Psicologia Clínica na área de Família e Casal (PUC-Rio).

** Professora titular do Departamento de Psicologia da PUC-Rio, Doutora em Psicologia Clínica pela PUC/SP, Pesquisadora 1A do CNPq e Orientadora da dissertação que deu origem ao manuscrito.

Financiamento: CAPES - Código de financiamento 001.

Este artigo de revista Estudos e Pesquisas em Psicologia é licenciado sob uma Licença Creative Commons Atribuição-Não Comercial 3.0 Não Adaptada. 